\title{
A Novel Intelligent System for Diagnosing some of Humans' Respiratory System Diseases
}

\author{
A. E. E. Elalfi \\ Computer science Department \\ Faculty of Specific Education \\ Mansoura University
}

\author{
M. E. E. Elalmi \\ Computer Science Department \\ Faculty of Specific Education \\ Mansoura University
}

\author{
F. A. Zahran \\ Computer Science Department \\ Faculty of Specific Education \\ Mansoura University
}

\begin{abstract}
This paper presents a novel intelligent system for diagnosing some of humans' respiratory diseases. The proposed system aims to simulate the real medical diagnosing processes. It was adopted in diagnosis on two main parts; knowledge base (KB) and image processing (IP). This paper combines two diagnostic methods; the decision tree (DT) method which used J48 algorithm in WEKA 3.7, and the gray level cooccurrence matrix (GLCM) method for extracting second order statistical texture features of chest x-ray images. The weighted euclidean distance (WED) algorithm was used for feature matching. The final decision calculated by probability measure method for independent events, which is depending on "multiplication rule". The proposed system implemented via visual studio.net 2017; used for designing the main graphical user interface (GUI), MATLAB17; used for image processing diagnoses, and LabVIEW17; used for knowledge base diagnoses. The obtained results show that there is a good agreement between expert's diagnoses and proposed system diagnoses with a high accuracy.
\end{abstract}

\section{Keywords}

Knowledge base, Image processing, Intelligent systems, Human respiratory system, Expert systems, Lab VIEW

\section{INTRODUCTION}

The respiratory system is one of the most important systems of the human body that saving functioning of other systems. so, its functional or structural disorders cause real threats [1]. The respiratory system can be divided into two sections: upper respiratory system and the lower respiratory system . Included in the upper respiratory system are the nostrils, nasal cavities, pharynx, epiglottis, and the larynx. The lower respiratory system consists of the trachea, bronchi, bronchioles, and the lungs[2]. Many of respiratory illnesses are the result of bacterial or viral infection of the lungs. Because people were constantly being exposed to harmful bacteria and viruses in their environment, their respiratory health can be adversely affected[3]. There are number of diseases that can cause problems with breathing. Some are simple infections, and others are disorders that can be quite serious, such as; chronic rhinitis, spasmodic laryngitis, chronic bronchitis, bronchiectasis, fibrous bronchitis, fibrous bronchitis, pulmonary atelectasis, lung cancer [4]. Training students who are future doctors is the aim of simulation, in order to facilitate the integration in the modern medical environment[5]. The development in computer technology has permitted the programmers and domain information specialists to build more brilliant tools for supporting doctors to determine the best decision[6]. Expert systems or systems of knowledge are considered the most popular kind of artificial intelligent systems in typical clinical work. They include knowledge of medications and can deal with information from individual patients to deduce reasoned conclusions. The knowledge in a proficient system is described in the shape of cluster of rules[7]. There are several types of knowledge representation techniques, the most common technique is the production rule which comprises if and then parts. Since the if part lists a set of conditions in some logical combinations and in the then part its problem solving action is taken, these two parts also called a condition and an action[8]. Medical diagnosis domain is one of the most important domains which apply and make great use of image processing procedures. Image processing is an important phase to improve the accuracy for diagnosis procedure[9]. The use of simulation is an educational tool which is becoming increasingly prevalent in health care. Institutions have dependent on simulations for helping educate their students and health care professionals; however, the evaluation of intervention effectiveness continues to be an area requiring research. With using of this technology, it has become necessary for evaluating this method of educating health care professionals[10]. Simulation is a technique that can be used to help understand and improve health care delivery; and constructive approaches to developing, testing, and improving health care delivery processes [11].

\section{RELATED WORK}

Marcin and Dawid presented a methodology implemented to simulate medical examinations of pulmonary diseases. They proposed bio methods modeled to work as the automated decision support in a process of diseased tissues detection over input $\mathrm{x}$-ray images. These methods have special features that with devoted modeling making them independently searching over the images with a good accuracy[12]. Yineng Zheng et al. proposed an innovative computer-assisted diagnosis system for chronic heart failure (CHF), based on cardiac reserve (CR) indexes extraction, heart sound hybrid characteristics extraction and intelligent diagnosis model definition. Statistical methods such as t-test and receiver operating characteristic (ROC) curve analysis and support vector machine (SVM) employed for the implementation of intelligent diagnosis. The results indicated the achieved diagnostic accuracy, sensitivity and specificity of the proposed system are $95.39 \%, 96.59 \%$ and $93.75 \%$ for the detection of CHF [13]. Dandl et al. presented a system provided classification between benign and malignant nodules with the help of neural networks model of self-organizing maps. The results performance values of $90.63 \%$ accuracy, $92.30 \%$ sensitivity and $89.47 \%$ specificity were acquired in the system which utilized a total of $128 \mathrm{CT}$ images obtained from 47 patients [14]. Chaurasia and Pal have compared the performance criterion of supervised learning classifiers, such as naı"ve bayes, SVM kernel, neural networks, decision tree $\mathrm{J} 48$, and regression tree, to find the best classifier in breast cancer datasets. The experimental result shows that SVM- 
RBF kernel is more accurate than other classifiers; it scores at the accuracy level of $96.84 \%$ in the breast cancer datasets[15]. Hossein Ahmadi et al. have conducted a systematic review for determining the contribution utilizing fuzzy logic methods in disease diagnosis in different medical practices. They selected eight scientific databases as an appropriate database and preferred reporting items for systematic reviews and meta-analyses (PRISMA) method was employed as the basis method for conducting that systematic and meta-analysis review. The results showed that the systematic review provided an appropriate platform for further research by identifying the research needs in the domain of disease [16]. Preeti and Renu have developed a lung nodule database by using content based image retrieval and algorithms for detection and classification of nodules. The results achieved an average precision of $88 \%$. Experimental studies show that the proposed parameters and analysis improves the semantic performance while reducing the computational complexity, reading and analyzing all slices by physicians [17]. Farahani et al. presented an approach based on a genetic algorithm to tune both the fuzzy rules and fuzzy sets. The results showed, the method was applied for making a proper decision for each patient [18]. Bawane and Shinde proposed a new classification algorithm for the efficient classification of lung tumor. The efficient classifiers based on multilayer perceptron (MLP) neural network. A separate cross-validation dataset is used for proper evaluation of the efficient classification of lung tumor. Optimal algorithm has been developed on the basis of the best classifier performance of $95.54 \%$ [19] . Vikas Chaurasia et al. used classification and regression tree (CART), iterative dichotomized 3(ID3), and decision table (DT) to predict the survivability for heart diseases patients. The results presented demonstrated that CART obtained higher accuracy within less time[20].

After researching and reconnaissance in previous studies; most previous studies were based on diagnosis mainly on symptoms only, while others focused on x-rays or CT in the diagnostic process. This makes the proposed system more distinctive and unique in the possibility of combining the symptoms and images in the process of diagnosis and diversity in the use of methodologies, algorithms and tools for design.

\section{THE PROPOSED FRAMEWORK DESCRIPTION}

The proposed system based on two parts for diagnosing namely; knowledge base and image processing. The first part is based on symptoms in diagnosing process and the second is based on chest $\mathrm{x}$-ray images. Figure 1 shows the proposed system framework.

\subsection{Diagnosis via Knowledge Base}

Knowledge base is one of two parts of the proposed system, which is dependent on following stages:

Basic knowledge about chest diseases and its associated symptoms was obtained through a database containing records of chest patients which previously diagnosed by more than one doctor in domain from Mansoura university hospital, department of chest diseases. Figure 2 shows the flowchart for diagnosing by symptoms.

Through personal interviews with specialist chest doctors and their discussion on the most important chest diseases; new dataset called "chest diseases" has been created for the proposed system.

Data preprocessing by removing of missing values, making sure that there are no incorrect data entered ,and selecting the attributes of dataset; which consisting of 100 instances derived from the database of the hospital, contains ten symptoms shown in Table 1, and nine basic diseases which are: chronic bronchitis(B), disease in coronary $\operatorname{artery}(\mathrm{C})$, pulmonary hypertension(D), lung cancer(E), pneumonia(G), thoracic allergy $(\mathrm{H})$, tuberculosis $(\mathrm{A})$, exhaustion $(\mathrm{F})$, and parasitic infections in the respiratory system(I).

Converting the type of database file to a file with a commaseparated values (CSV) format, and call it as a training dataset through waikato environment for knowledge analysis (WEKA 3.7), which is a data mining platform based on java with open source code, which gathers many machine learning algorithms to mine data, including cluster class, data pretreatment, classification, , visual interactive page, and association rule mining [21]. Figure 3 shows samples of training dataset which is called "chest diseases".

Applying classification algorithm $\mathrm{J} 48$ for producing the decision tree and the rules. After the decision tree generated, there are only eight features that affect to a classification instead of ten features, this means; laying out only those decision or symptoms that are important and consequences to clasify a various type of diseases. 


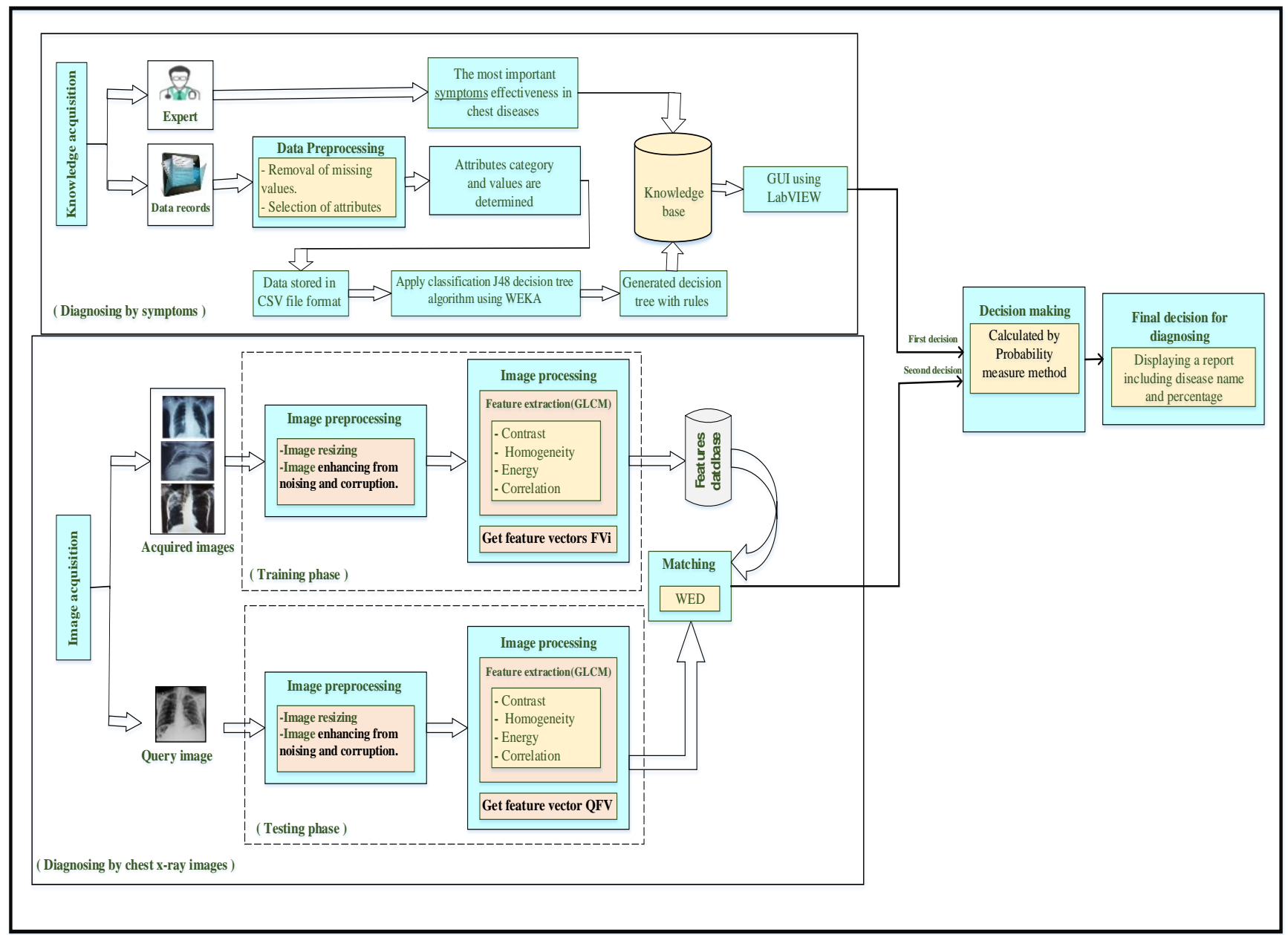

Fig 1: The proposed framework 


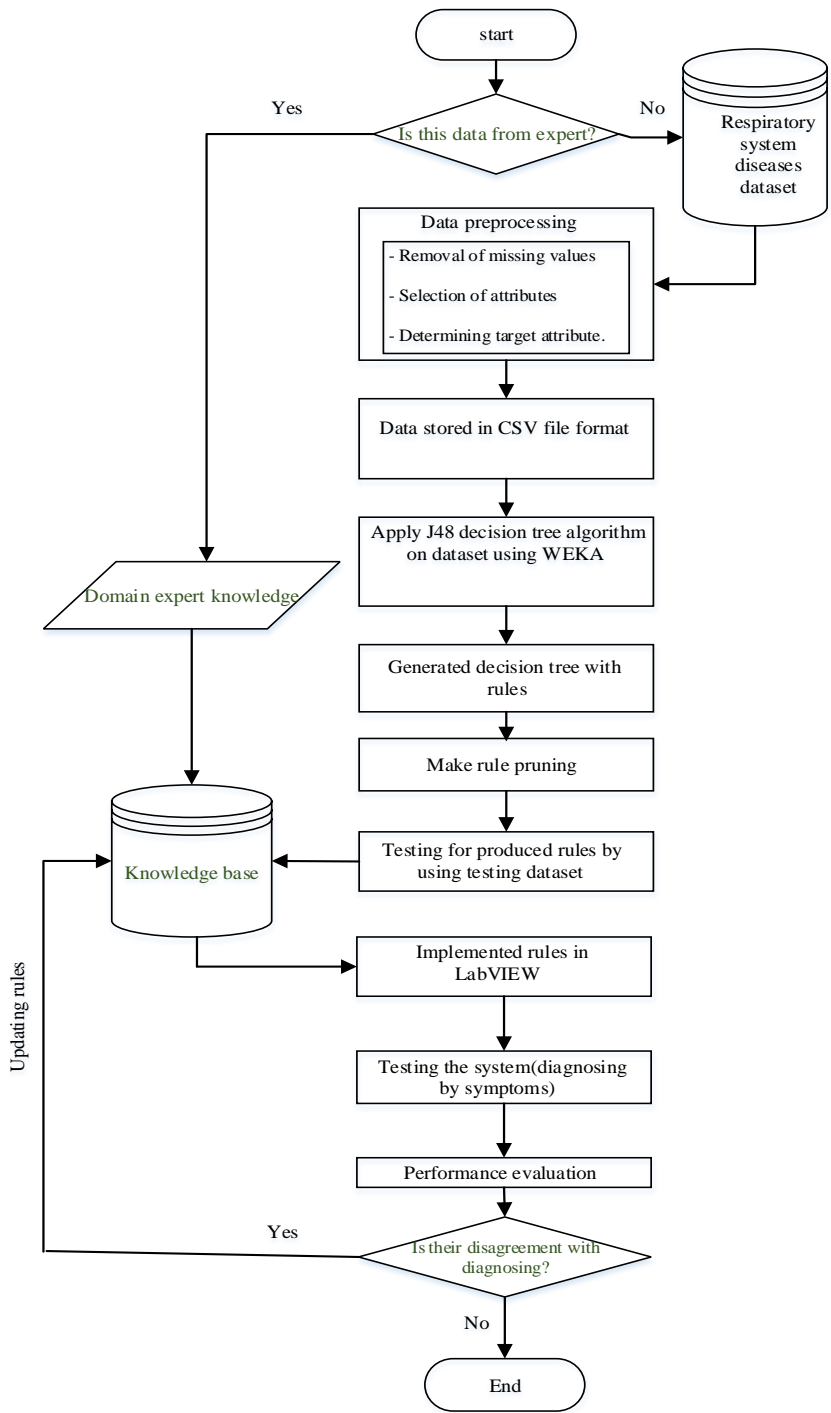

Fig 2: KB flowchart for diagnosing by symptoms

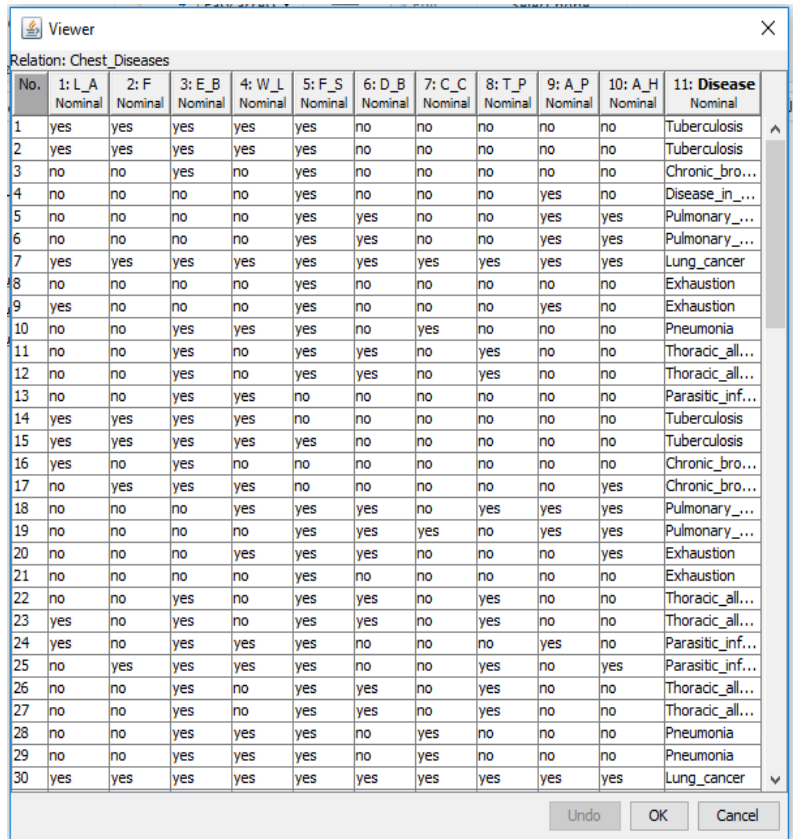

Fig 3: Samples of training dataset
Table 1. Symptoms abbreviation of the proposed chest diseases

\begin{tabular}{|c|l|c|c|}
\hline No. & \multicolumn{1}{|c|}{ Symptoms } & Description & Value \\
\hline 1 & Loss of Appetite for food & L_A & Yes/No \\
\hline 2 & Fever & F & Yes/No \\
\hline 3 & $\begin{array}{l}\text { Exits Blood with } \\
\text { tranghing blood } \\
\text { transfusion }\end{array}$ & E_B & Yes/No \\
\hline 4 & Weight Loss & W_L & Yes/No \\
\hline 5 & Feeling Sick in general & F_S & Yes/No \\
\hline 6 & Difficulty Breathing & D_B & Yes/No \\
\hline 7 & Chronic Cough & C_C & Yes/No \\
\hline 8 & $\begin{array}{l}\text { Thoracic Pain or worsens } \\
\text { when breathing or }\end{array}$ & T_P & Yes/No \\
\hline 9 & Angina Pectoris & A_P & Yes/No \\
\hline 10 & Accelerate Heartbeat & A_H & Yes/No \\
\hline
\end{tabular}

The visualization of decision tree shows 10 leaves node with 19 of the tree size shows in Figure 4.

Ten rules performed from the pruned decision tree as follows:

(1) $\quad$ IF E_B $=\mathrm{Yes}^{\wedge} \mathrm{W} \_\mathrm{L}=\mathrm{Yes} \wedge{ }^{\wedge} \mathrm{L} \_\mathrm{A}=\mathrm{Yes} \wedge{ }^{\wedge} \mathrm{D} \_\mathrm{B}=$ Yes THEN Disease $=$ "Lung_cancer"

(2) $\quad \mathrm{IF}$ E_B $=\mathrm{Yes}^{\wedge} \mathrm{W} \_\mathrm{L}=\mathrm{Yes} \wedge{ }^{\wedge} \mathrm{L} \_\mathrm{A}=\mathrm{Yes} \wedge{ }^{\wedge} \mathrm{D} \_\mathrm{B}=$ $\mathrm{No}^{\wedge} \mathrm{F}=$ Yes THEN Disease $=$ "Tuberculosis"

(3) $\quad \mathrm{IFE} \mathrm{B}=\mathrm{Yes}^{\wedge} \mathrm{W} L \mathrm{~L}=\mathrm{Yes} \wedge{ }^{\wedge} \mathrm{L} A \mathrm{~A}=\mathrm{Yes} \wedge{ }^{\wedge} \mathrm{D} \_\mathrm{B}=$ $\mathrm{No}^{\wedge} \mathrm{F}=$ No THEN Disease $=$ "Pneumonia"

(4) $\quad \mathrm{IF} E \_B=\mathrm{Yes} \wedge{ }^{\wedge} \mathrm{W} \_\mathrm{L}=\mathrm{Yes} \wedge{ }^{\wedge} \mathrm{L} \_\mathrm{A}=\mathrm{No}{ }^{\wedge} \mathrm{C} \_\mathrm{C}=$ Yes THEN Disease $=$ "Pneumonia"

(5) $\quad \mathrm{IF}$ E_B $=\mathrm{Yes} \wedge{ }^{\wedge} \mathrm{W} \_\mathrm{L}=\mathrm{Yes} \wedge{ }^{\wedge} \mathrm{L} \_\mathrm{A}=\mathrm{No}{ }^{\wedge} \mathrm{C} \_\mathrm{C}=$ No THEN Disease = "Parasitic_infections_in_the_respiratory_system"

(6) IF E_B $=$ Yes ${ }^{\wedge} \mathrm{W} \_\mathrm{L}=\mathrm{No}{ }^{\wedge} \mathrm{D} \_\mathrm{B}=\mathrm{Yes}$ THEN Disease $=$ " Thoracic_allergy"

(7) IF E_B $=$ Yes $\wedge$ W_L $=$ No $\wedge$ D_B $=$ No THEN Disease $=$ "Chronic_bronchitis"

(8) $\quad$ IF E B $=\mathrm{No}^{\wedge} \mathrm{A} \mathrm{P}=\mathrm{Yes} \wedge \mathrm{A} \mathrm{H}=$ Yes THEN Disease $=$ " Pulmonary_hypertension"

(9) IF E_B $=\mathrm{No}^{\wedge} \mathrm{A} \mathrm{P}=\mathrm{Yes} \wedge \mathrm{A} \_\mathrm{H}=\mathrm{No}$ THEN Disease $=$ " Disease_in_Coronary_artery"

(10) $\mathrm{IF}$ E_B $=$ No $\wedge$ A P $=$ No THEN Disease $=$ "Exhaustion"

Programming rules in laboratory virtual instrument engineering workbench (LabVIEW17), which is a system design platform and development environment for a visual programming language from national instruments (NI) [22]. Figure 5 shows sample of cases for the block diagram of the proposed system KB. Figure 6 shows the block diagram of the proposed system $\mathrm{KB}$.

Designing GUI to facilitate the presentation of the appropriate diagnosis. Figure7 shows front panel of the proposed system KB. 
This section talked about diagnosis through symptoms. As the diagnosis of chest diseases most often confirmed by a chest $\mathrm{x}$ ray; there was a need to add the part of image processing in the proposed system to make the diagnosis process more efficient and effective.

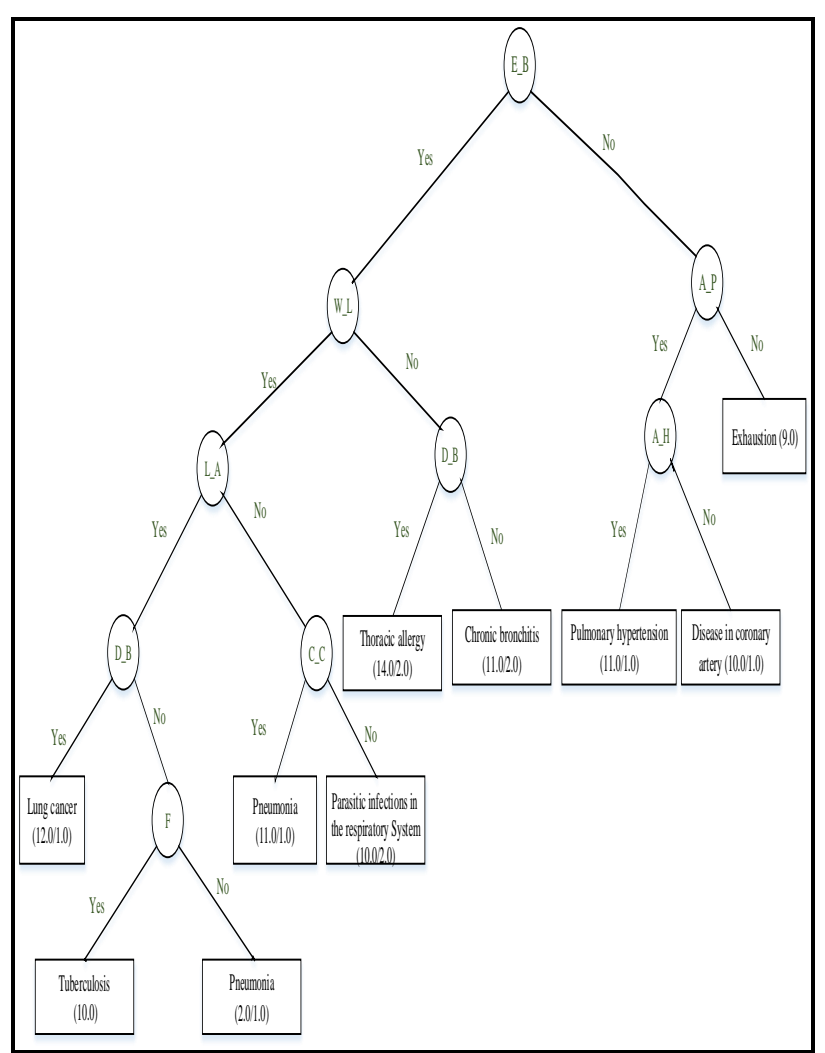

Fig 4: Decision tree for extracted rules from J48 algorithm

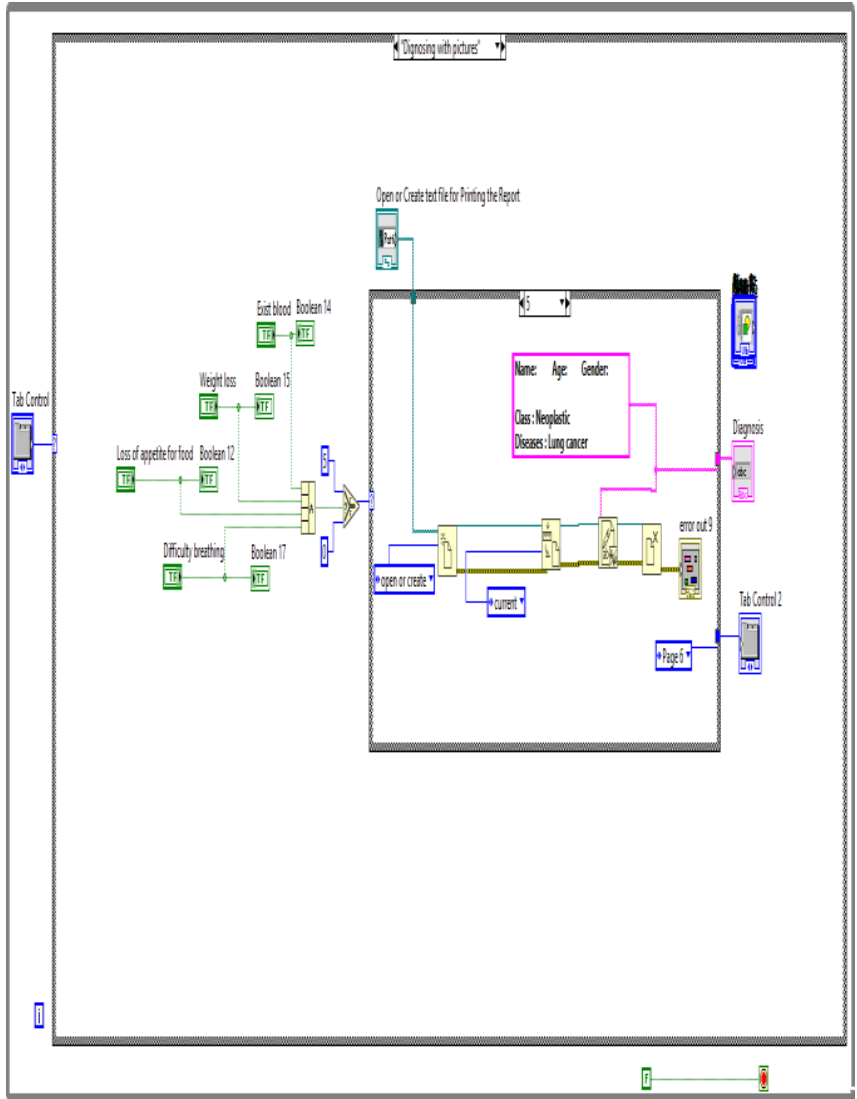

Fig 5: Sample of cases for the block diagram 


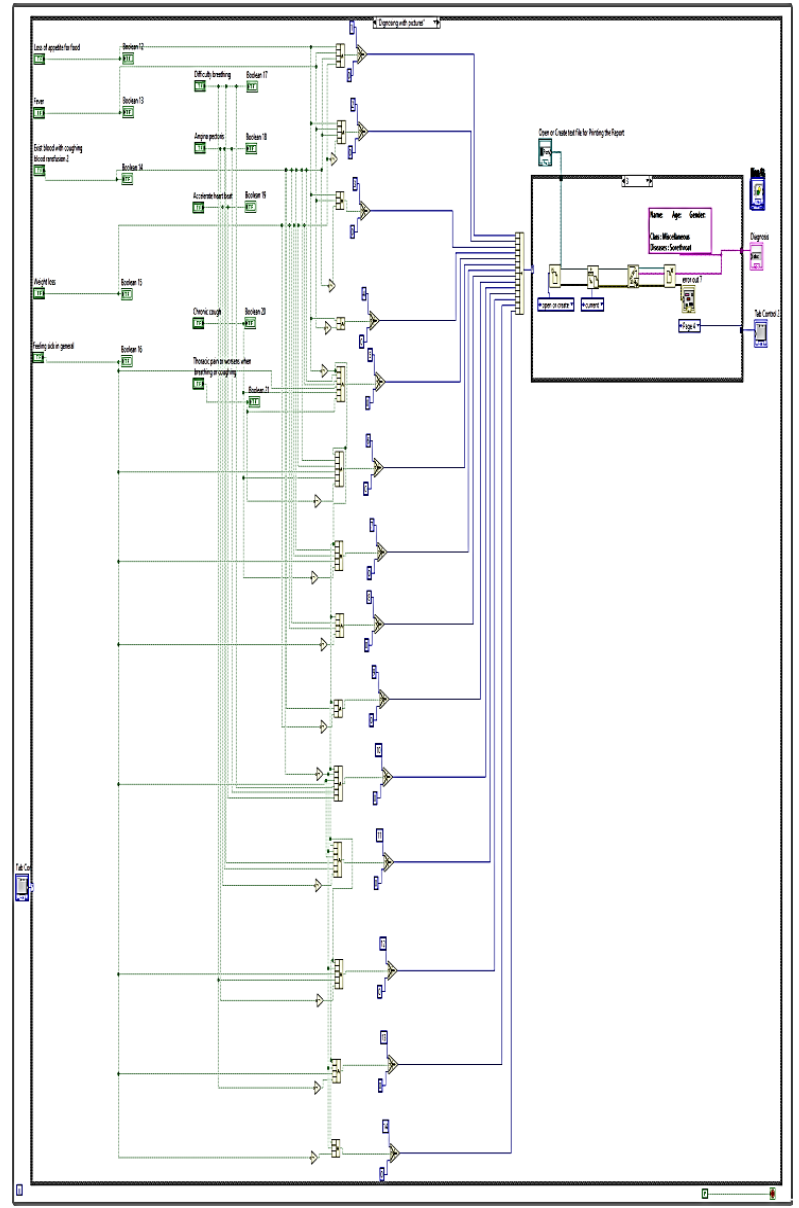

Fig 6: The block diagram of instances used in diagnosing by symptoms

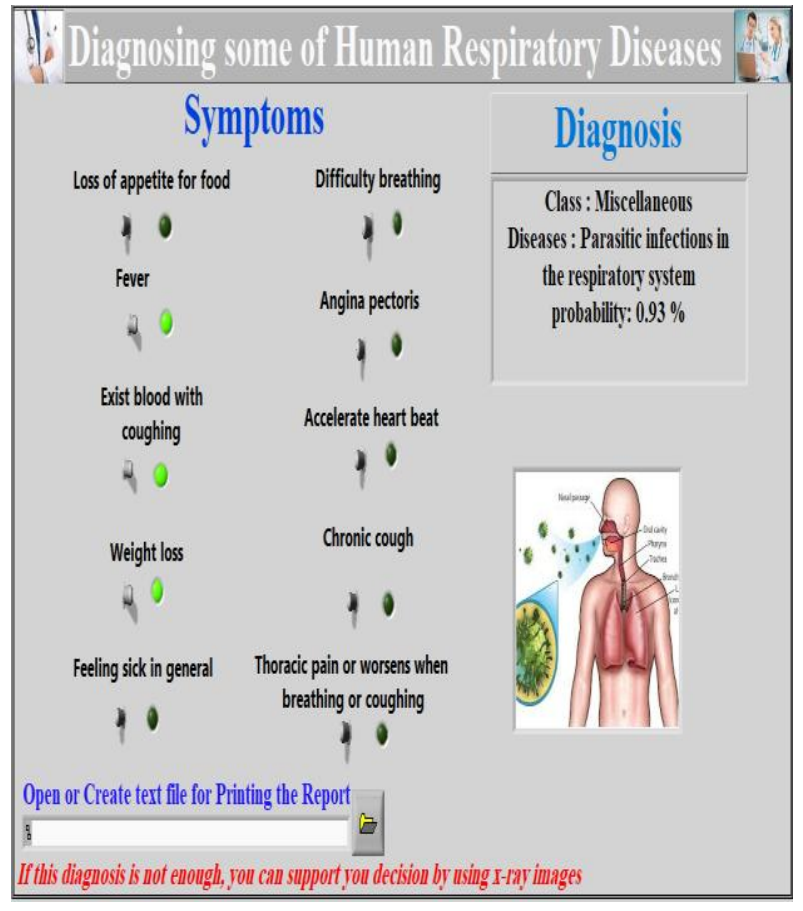

Fig 7: The front panel for diagnosing by symptoms

\subsection{Diagnosing via Image Processing}

Image processing is a technique to improve images received from cameras or sensors placed on satellites, space probes, medical images, and pictures taken in normal life for various applications[23]. Image processing is the other important part of the proposed system, it can be divided into two main phases, training phase and testing phase as shown in Figure 8.

In the training phase, the image acquisition, image preprocessing and image feature extraction are performed.

In image acquisition, classified chest $\mathrm{x}$-ray images were collected from department of radiology in Mansoura University, radiology centers Eleman and Elmogi in Mansoura, and from the internet.

After collecting chest x-ray images, they were presented to five experts in domain to review their classification, and divided them into classes. Table 2 shows samples of chest $\mathrm{x}$ ray image.

In image pre-processing, the image is resizing and enhancing from noising and corruption.

Table 2. Samples of chest $x$-ray images

\begin{tabular}{|c|c|c|}
\hline $\begin{array}{c}\text { Chest x-ray } \\
\text { images }\end{array}$ & Disease Class & Disease Name \\
\hline & Inflammatory & Tuberculosis \\
\hline & Miscellaneous & $\begin{array}{c}\text { Parasitic infections in } \\
\text { the respiratory system }\end{array}$ \\
\hline & Normal & Exhaustion \\
\hline
\end{tabular}

Chest x-ray images feature extraction technique is GLCM, which is a classic method of texture feature extraction that effective in image recognition, image retrieval, image segmentation, , and image classification[24].

The main four extracted features from GLCM are:

\section{- Contrast}

Contrast is a local grey level variation in the grey level cooccurrence matrix. It can be represented by a linear reliance of grey levels of neighboring pixels.

Contrast $=\sum_{\mathrm{i}, \mathrm{j}}|\mathrm{i}-\mathrm{j}|^{2} \mathrm{P}(\mathrm{i}, \mathrm{j})$

Where, $i$ and $j$ are the vertical and horizontal cell coordinates and $\mathrm{p}$ is the cell value. 
- Homogeneity

Homogeneity is very important feature. It uses the inverse of contrast weight to weight values. It also, measures the level of uniformity of the non-zero entries in the GLCM.

$$
\text { Homogeneity }=\underset{i, j 1-(i-j)^{2}}{\sum} \frac{1}{(i, j)}
$$

- Energy

Energy represents the opposite of the Entropy as it works like a measure of local homogeneity. Simply this feature will demonstrate how much uniformity the texture is.

$$
\operatorname{Energy}=\sum_{\mathbf{i}, \mathbf{j}} \mathbf{p}(\mathbf{i}, \mathbf{j})^{2}
$$

Where, $i$ and $j$ : row and column numbers in the GLCM matrix.

$$
\begin{aligned}
& \text { Correlation } \\
& \text { Correlation }=\sum_{\mathrm{i}=0}^{\mathrm{G}=1} \sum_{\mathrm{j}=0}^{\mathrm{G}=1} \frac{\mathrm{ijP}(\mathrm{i}, \mathrm{j})-\left(\mathrm{m}_{\mathrm{i}} \mathrm{m}_{\mathrm{j}}\right)}{\sigma_{\mathrm{i}} \sigma_{\mathrm{j}}}
\end{aligned}
$$

Where, $\sigma_{i}$ and $m_{i}$ are the mean and standard deviation of $\mathrm{P}$ $(i, \mathrm{j})$ rows, $m_{j}$ and $\sigma_{j}$ the mean and standard deviation of $\mathrm{P}(i, \mathrm{j})$ columns, respectively[25].

The previous features can be included in the next feature vector:

$\mathrm{FV}_{i}=[\mathrm{E}, \mathrm{C}, \mathrm{COR}, \mathrm{H}]$

Where, $\mathrm{FV}_{i}$ is a feature vector, $i$ is a number of image, $\mathrm{E}$ is energy, $\mathrm{C}$ is contrast, $\mathrm{COR}$ is correlation, and $\mathrm{H}$ is homogeneity.

The previous steps will be represented until all the chest x-ray images finished. Then all patterns are saved in a data base for pattern learning.
In the testing phase, a query image is received. Then, the features of this image are extracted and formulated in a query feature vector.

$\mathrm{QFV}=[\mathrm{E}, \mathrm{C}, \mathrm{COR}, \mathrm{H}]$

Where, $\mathrm{QV}$ is a query feature vector.

WED technique is used for matching process, which passed from the following steps: vectors $\mathrm{FV}_{i}$

Finding the WED among the QFV and all

- The formula of WED measure is demonstrated as follows[25]:

$\mathrm{d}\left(v, v^{k}\right)=\sqrt{\sum_{i=1}^{n} p_{i}\left(v_{i}-v_{i}^{k}\right)^{2}}$

Where:

$v_{i}$ to balance the variations in the dynamic range.

$p_{i}$ the weight added to the component.

$k$ is the matched image index.

$p_{i}=\frac{N}{\sum_{k-1}^{N}\left(v_{i}^{k}-\bar{v}_{l}\right)^{2}}$

$N=$ the number of images in databases.

$\overline{v_{l}}=\frac{\sum_{K=1}^{N} v_{i}^{k}}{N}$

- $\quad$ Sorting the WED values. the WED

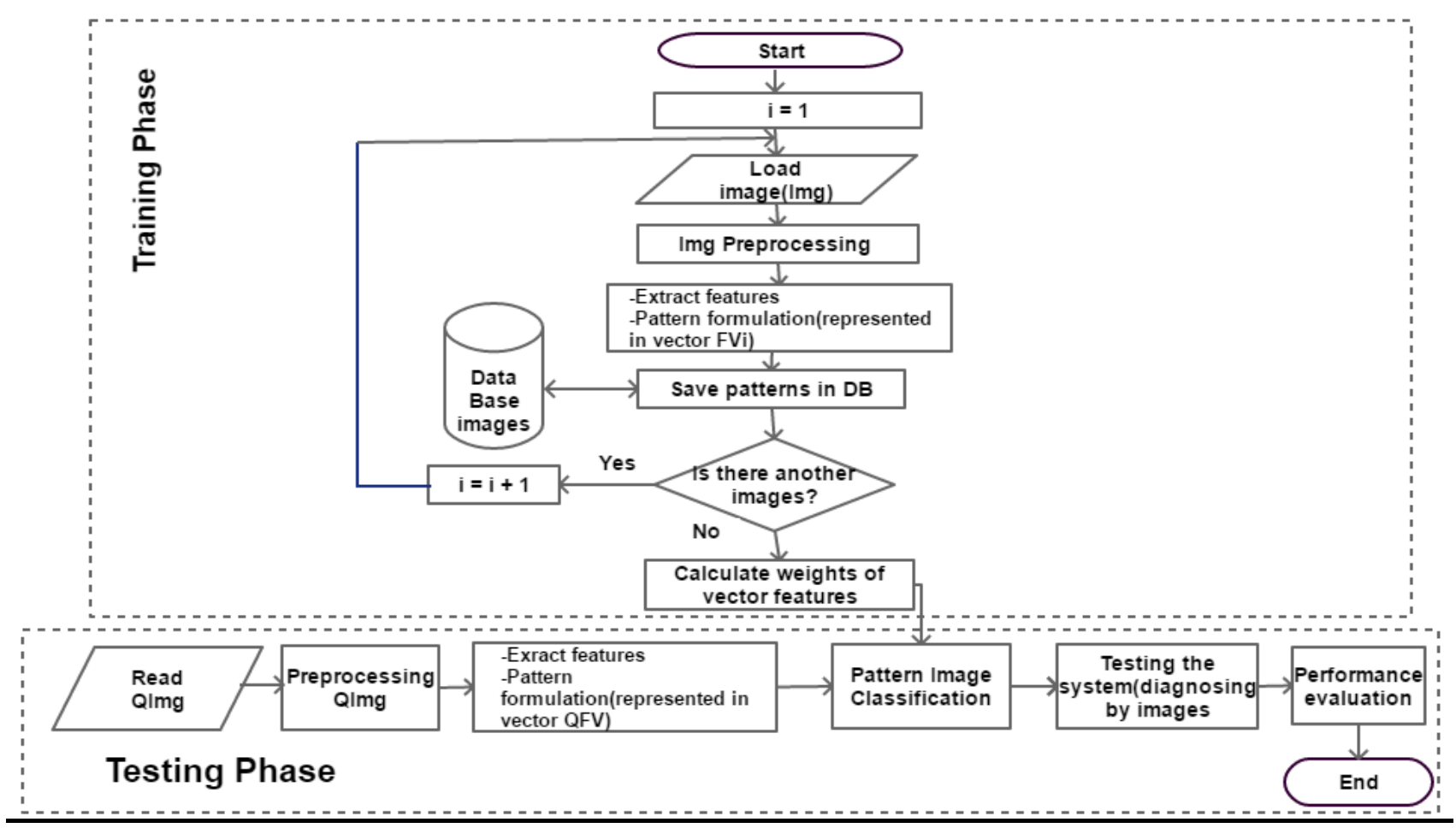

Fig 8: Flowchart for diagnosing chest $x$-ray images 


\section{APPLICATION AND EXPERIMENTAL RESULTS}

\subsection{Application}

The knowledge dataset (100 instances) of the proposed system, were collected from Mansoura university hospital, department of chest diseases, represented in ten symptoms leading to nine chest diseases.

Chest x-ray images database (215 images) were collected from department of radiology in Mansoura university, radiology centers Eleman and Elmogi in Mansoura, and from the internet, classified into four basic classes based on the opinion of experts in domain as shown in Table 3.

The proposed system implemented via visual studio.net 2017; used for designing the main GUI, matlab17; used for image processing diagnoses, and LabVIEW17 ; used for knowledge base diagnoses.

\section{Table 3. Images distribution across classes}

\begin{tabular}{ccc}
\hline $\begin{array}{c}\text { Class } \\
\text { Number }\end{array}$ & Class name & Number of images \\
\hline $\mathbf{1}$ & Inflammatory (INF) & 60 \\
$\mathbf{2}$ & Miscellaneous (MIS) & 40 \\
$\mathbf{3}$ & Neoplastic (NEO) & 15 \\
$\mathbf{4}$ & Normal (NOR) & 100 \\
\hline & Total & 215 \\
\hline
\end{tabular}

Figure 9 shows the proposed system GUI, introducing basic information about human respiratory system components, and functions. In addition to the main part of the proposed system for diagnosing some of human's respiratory diseases.

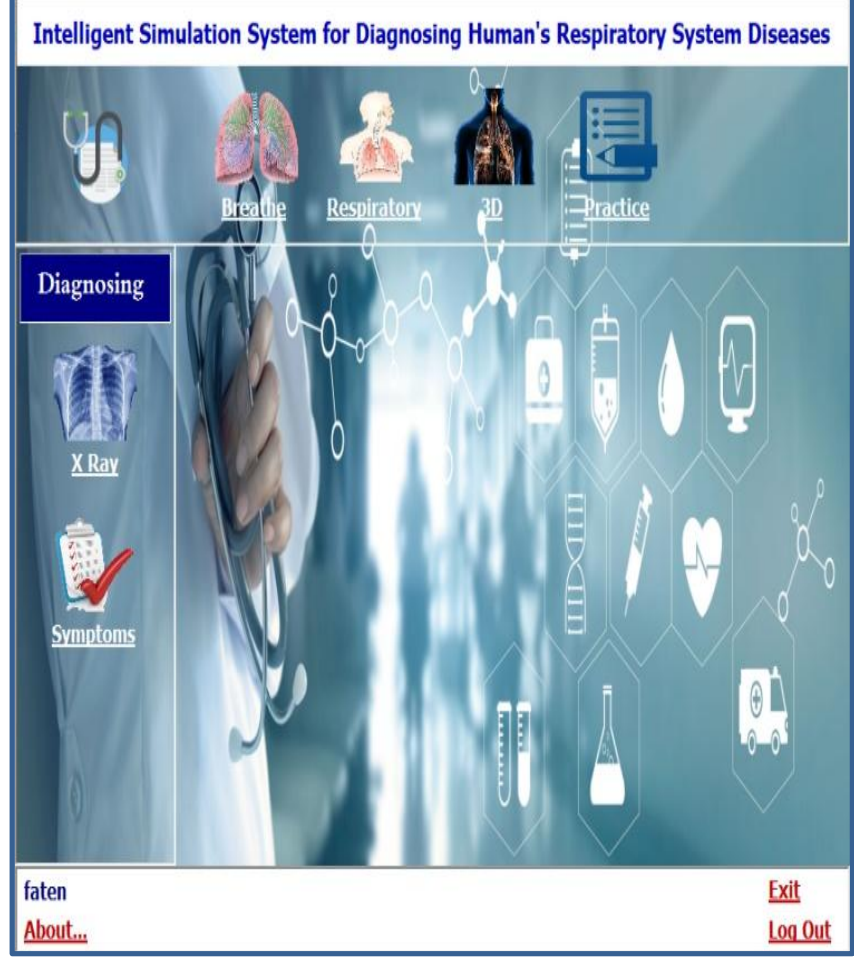

Fig 9: The proposed system GUI
Figure7 shows the front panel for diagnosing by symptoms. Fig. 5 shows the block diagram of instances used in diagnosing by symptoms. This stage produces the name of the disease.

Figure10 shows GUI for chest x-ray images, including query image, the nearest five images to query image.

This stage presenting the disease name, retrieved images related with the query image, and the percentage of similarity between a query image and images in the data base.

Since the diagnosing from $\mathrm{KB}$ and diagnosing from image processing are two independent events then the final decision probability can be given by probability of A multiply by the probability of B as follows [26]:

$\mathrm{P}(\mathrm{A} \cap \mathrm{B})=\mathrm{P}(\mathrm{A}) . \mathrm{P}(\mathrm{B})$

Where:

$A$ and $B$ are events of the probability.

$\mathrm{P}(\mathrm{A})$ is the probability of event $\mathrm{A}$, which is the set function $\mathrm{P}$ that assigns to event $\mathrm{A}$.

$\mathrm{P}(\mathrm{B})$ is the probability of event $\mathrm{B}$, which is the set function $\mathrm{P}$ that assigns to event $\mathrm{B}$.

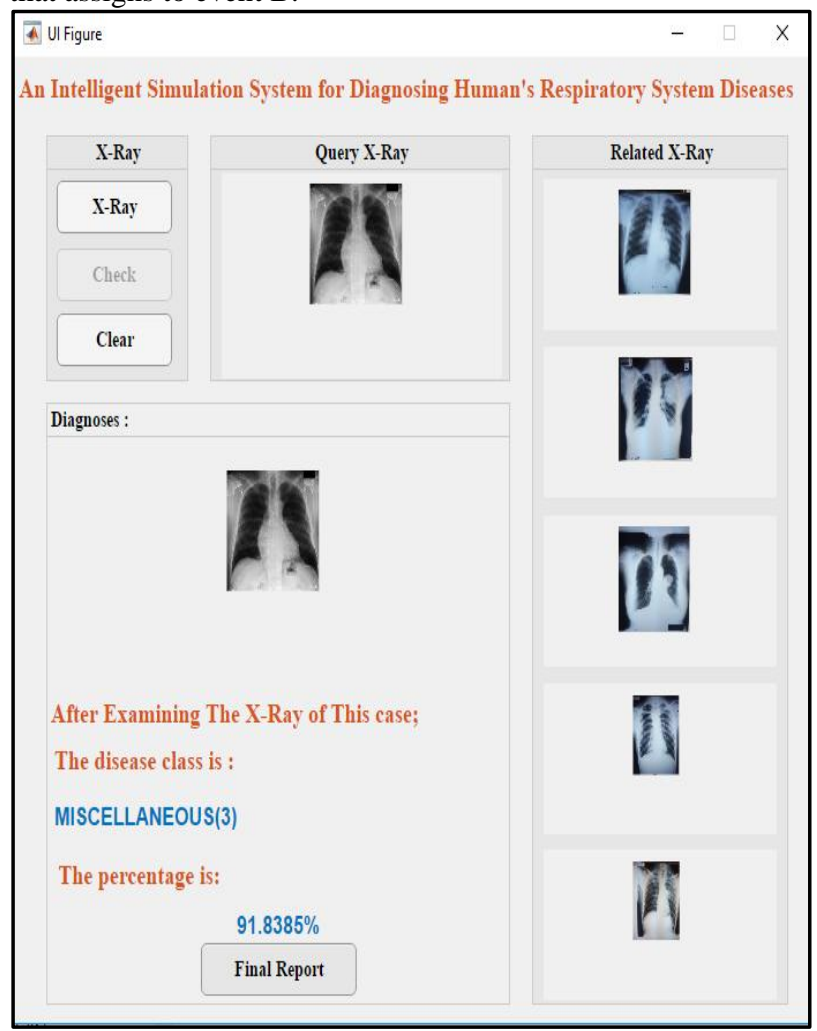

Fig 10: GUI for diagnosing by chest $x$-ray images

\subsection{Experimental Results}

For testing and evaluating performance of diagnosing by symptoms, thirty instances were used as a testing dataset classified by three experts in domain. The results in Table 4 show basic evaluation measures for diagnosing by symptoms which achieves high accuracy with percentage $0.97 \%$ with error rate $0.03 \%$. Table 5 shows its confusion matrix.For testing and evaluating performance of diagnosing by chest $\mathrm{x}$ ray images, (155 chest x-ray images) were collected and classified by five experts in domain, then divided into four classes as shown in Table 6 
Table 4. Basic evaluation measures for diagnosing by symptoms

\begin{tabular}{|c|c|c|c|c|c|c|c|c|}
\hline $\begin{array}{c}\text { Dise } \\
\text { ase } \\
\begin{array}{c}\text { Nam } \\
\text { e }\end{array}\end{array}$ & $\begin{array}{c}\mathrm{T} \\
\mathrm{P}\end{array}$ & $\begin{array}{c}\mathrm{T} \\
\mathrm{N}\end{array}$ & $\begin{array}{c}\mathrm{F} \\
\mathrm{P}\end{array}$ & $\begin{array}{c}\mathrm{F} \\
\mathrm{N}\end{array}$ & $\begin{array}{c}\text { Precisi } \\
\text { on }\end{array}$ & $\begin{array}{c}\text { Sensit } \\
\text { ivity }\end{array}$ & $\begin{array}{c}\text { Specificit } \\
\mathrm{y}\end{array}$ & $\begin{array}{c}\mathrm{F}- \\
\mathrm{me} \\
\mathrm{asu} \\
\mathrm{re}\end{array}$ \\
\hline $\mathrm{A}$ & 4 & 26 & 0 & 0 & 1.00 & 1.00 & 1.00 & $\begin{array}{c}1.0 \\
0\end{array}$ \\
\hline $\mathrm{B}$ & 3 & 27 & 0 & 0 & 1.00 & 1.00 & 1.00 & $\begin{array}{c}1.0 \\
0\end{array}$ \\
\hline $\mathrm{C}$ & 1 & 28 & 1 & 0 & 0.50 & 1.00 & 0.97 & $\begin{array}{c}0.6 \\
7\end{array}$ \\
\hline $\mathrm{D}$ & 4 & 26 & 0 & 0 & 1.00 & 1.00 & 1.00 & $\begin{array}{c}1.0 \\
0\end{array}$ \\
\hline $\mathrm{E}$ & 2 & 24 & 0 & 0 & 1.00 & 1.00 & 1.00 & $\begin{array}{c}1.0 \\
0\end{array}$ \\
\hline $\mathrm{F}$ & 3 & 27 & 0 & 1 & 1.00 & 0.75 & 1.00 & $\begin{array}{c}0.8 \\
6\end{array}$ \\
\hline $\mathrm{G}$ & 3 & 27 & 0 & 0 & 1.00 & 1.00 & 1.00 & $\begin{array}{c}1.0 \\
0\end{array}$ \\
\hline $\mathrm{H}$ & 6 & 24 & 0 & 0 & 1.00 & 1.00 & 1.00 & $\begin{array}{c}1.0 \\
0\end{array}$ \\
\hline $\mathrm{I}$ & 3 & 27 & 0 & 0 & 1.00 & 1.00 & 1.00 & $\begin{array}{c}1.0 \\
0\end{array}$ \\
\hline
\end{tabular}

Table 5. The confusion matrix for diagnosing by symptoms

\section{$\begin{array}{lllllllll}\text { A } & \text { B } & \text { C } & \text { D } & \text { E } & \text { F } & \text { G } & \text { H } & \text { I }\end{array}$}

\begin{tabular}{l|l|l|l|l|l|l|l|l|l|}
\cline { 2 - 10 } B & \multicolumn{1}{|l|}{4} & 0 & 0 & 0 & 0 & 0 & 0 & 0 & 0 \\
\cline { 2 - 10 } C & 0 & 3 & 0 & 0 & 0 & 0 & 0 & 0 & 0 \\
\cline { 2 - 10 } D & 0 & 0 & 1 & 0 & 0 & 0 & 0 & 0 & 0 \\
\cline { 2 - 10 } E & 0 & 0 & 0 & 4 & 0 & 0 & 0 & 0 & 0 \\
\cline { 2 - 10 } F & 0 & 0 & 0 & 0 & 2 & 0 & 0 & 0 & 0 \\
\cline { 2 - 10 } G & 0 & 0 & 1 & 0 & 0 & 3 & 0 & 0 & 0 \\
\cline { 2 - 10 } H & 0 & 0 & 0 & 0 & 0 & 0 & 3 & 0 & 0 \\
\cline { 2 - 10 } I & 0 & 0 & 0 & 0 & 0 & 0 & 0 & 6 & 0 \\
\cline { 2 - 10 } & 0 & 0 & 0 & 0 & 0 & 0 & 0 & 0 & 3 \\
\cline { 2 - 10 }
\end{tabular}

Table 6. The confusion matrix for diagnosing by chest $x$-ray images

\begin{tabular}{|c|c|c|c|c|c|c|c|c|}
\hline $\begin{array}{c}\text { Dise } \\
\text { ase } \\
\text { Nam } \\
\text { }\end{array}$ & $\begin{array}{c}\mathrm{T} \\
\mathrm{P}\end{array}$ & $\begin{array}{c}\mathrm{T} \\
\mathrm{N}\end{array}$ & $\begin{array}{c}\mathrm{F} \\
\mathrm{P}\end{array}$ & $\begin{array}{c}\mathrm{F} \\
\mathrm{N}\end{array}$ & $\begin{array}{c}\text { Precisi } \\
\text { on }\end{array}$ & $\begin{array}{c}\text { Sensitiv } \\
\text { ity }\end{array}$ & $\begin{array}{c}\text { Specifici } \\
\text { ty }\end{array}$ & $\begin{array}{c}\mathrm{F}- \\
\text { meas } \\
\text { ure }\end{array}$ \\
\hline $\mathrm{A}$ & 4 & 26 & 0 & 0 & 1.00 & 1.00 & 1.00 & 1.00 \\
\hline $\mathrm{B}$ & 3 & 27 & 0 & 0 & 1.00 & 1.00 & 1.00 & 1.00 \\
\hline $\mathrm{C}$ & 1 & 28 & 1 & 0 & 0.50 & 1.00 & 0.97 & 0.67 \\
\hline $\mathrm{D}$ & 4 & 26 & 0 & 0 & 1.00 & 1.00 & 1.00 & 1.00 \\
\hline $\mathrm{E}$ & 2 & 24 & 0 & 0 & 1.00 & 1.00 & 1.00 & 1.00 \\
\hline $\mathrm{F}$ & 3 & 27 & 0 & 1 & 1.00 & 0.75 & 1.00 & 0.86 \\
\hline $\mathrm{G}$ & 3 & 27 & 0 & 0 & 1.00 & 1.00 & 1.00 & 1.00 \\
\hline $\mathrm{H}$ & 6 & 24 & 0 & 0 & 1.00 & 1.00 & 1.00 & 1.00 \\
\hline $\mathrm{I}$ & 3 & 27 & 0 & 0 & 1.00 & 1.00 & 1.00 & 1.00 \\
\hline \multicolumn{3}{|c|}{ Average } & & 0.94 & 0.97 & 1.00 & 0.95 \\
\hline
\end{tabular}

Table7 shows statistical measures applied to determine the efficiency of diagnosing by images [27-30].

Table 7. Basic evaluation measures for diagnosing by chest images

\begin{tabular}{|c|c|c|c|c|c|c|c|c|}
\hline $\begin{array}{l}\text { Class } \\
\text { Nam } \\
\text { e }\end{array}$ & TP & $\mathrm{TN}$ & $\begin{array}{l}\mathrm{F} \\
\mathrm{P}\end{array}$ & FN & $\begin{array}{c}\text { Precisi } \\
\text { on }\end{array}$ & $\begin{array}{l}\text { Sensiti } \\
\text { vity }\end{array}$ & $\begin{array}{c}\text { Specifi } \\
\text { city }\end{array}$ & $\begin{array}{c}\text { F- } \\
\text { me } \\
\text { asu } \\
\text { re }\end{array}$ \\
\hline INF & 48 & 104 & 1 & 2 & 0.98 & 0.96 & 0.99 & $\begin{array}{c}0.9 \\
7\end{array}$ \\
\hline MIS & 39 & 113 & 2 & 1 & 0.95 & 0.98 & 0.98 & $\begin{array}{c}0.9 \\
6\end{array}$ \\
\hline NOR & 48 & 103 & 2 & 2 & 0.96 & 0.96 & 0.98 & $\begin{array}{c}0.9 \\
6\end{array}$ \\
\hline NEO & 14 & 139 & 1 & 1 & 0.93 & 0.93 & 0.99 & $\begin{array}{c}0.9 \\
3\end{array}$ \\
\hline \multicolumn{5}{|c|}{ Average } & 0.96 & 0.96 & 0.99 & $\begin{array}{c}0.9 \\
6\end{array}$ \\
\hline
\end{tabular}

Accuracy $=\frac{\text { Sum of correct classifications }}{\text { Total number of classifications }}$

Accuracy $=0.96 \%$

Accuracy is the overall accuracy for diagnosing by images.

Error Rate $=1-$ Accuracy

Error Rate $=1-0.94=0.04 \%$

Error Rate is the overall error rate for diagnosing by images. 


\section{CONCLUSIONS AND FUTURE WORK}

The diagnosis is an important process in the medical field, the proposed system helps in diagnosing of some diseases of the human respiratory system by combining the knowledge base and image processing with the possibility of saving time and effort decision-making in the process of diagnosis.

The proposed system can be used to confirm doctors' decision.

According to experimental results the system achieves high accuracy which increases the efficiency of the system and its validity for use.

The final decision calculated by probability measure method for independent events, which is depending on "multiplication rule".

The results can be improved in future work by extending and designing large knowledge base for the other respiratory system diseases, and extending the proposed system of this study to other fields and categories and integrating image processing, sound processing, and knowledge base in building a diagnostic intelligent system.

\section{REFERENCES}

[1] Redlarski, G. and J. Jaworski, A new approach to modeling of selected human respiratory system diseases, directed to computer simulations. Comput Biol Med, 2013. 43(10): p. 1606-1613.

[2] Levitzky, M.G., Function and Structure of the Respiratory System. 8th ed. 2013, United States of America: McGraw-Hill.

[3] Spinola, H., HLA Loci and Respiratory Infectious Diseases. Journal of Respiratory Research, 2016. 2(3): p. 56-66.

[4] Restrepo, M.I., et al., Year in review 2016: Respiratory infections, acute respiratory distress syndrome, pleural diseases, lung cancer and interventional pulmonology. Respirology, 2017. 22(3): p. 602-611.

[5] Toader, E., Clinical Simulations for Learning Medical Skills: A Work-based Approach to Simulators. Procedia Social and Behavioral Sciences, 2015. 197: p. 24432448 .

[6] Dutta, T., et al., An Intuition Based Fuzzy Logic Driven Approach for Designing Symptomatic Medical Diagnostic Expert System. International Journal of Engineering Research \& Technology (IJERT), 2015. 4(02): p. 876-878.

[7] Er, O., N. Yumusak, and F. Temurtas, Diagnosis of chest diseases using artificial immune system. Expert Systems with Applications, 2012. 39(2): p. 1862-1868.

[8] Bursuk, E., S. Demirci, and M.A. Korpinar, Expert system in medicine and its application for pulmonary diseases. Medical Science and Discovery, 2016. 3(11): p. 342.

[9] Arena, P., et al., Image processing for medical diagnosis using CNN. Nuclear instruments \& methods in physics research. Section A, Accelerators, spectrometers, detectors and associated equipment., 2003. 497(1): p. 174.
[10] Harder, B.N., Use of simulation in teaching and learning in health sciences: a systematic review. J Nurs Educ, 2010. 49(1): p. 23-8.

[11] Kearney, J.A. and E.S. Deutsch, Using Simulation to Improve Systems. Otolaryngologic Clinics of North America, 2017. 50(5): p. 1015-1028.

[12] Woźniak, M. and D. Połap, Bio-inspired methods modeled for respiratory disease detection from medical images. Swarm and Evolutionary Computation, 2018. 41: p. 69-96.

[13] Zheng, Y., et al., Computer-assisted diagnosis for chronic heart failure by the analysis of their cardiac reserve and heart sound characteristics. Comput Methods Programs Biomed, 2015. 122(3): p. 372-83.

[14] Dand11, E., et al. Artificial neural network-based classification system for lung nodules on computed tomography scans. in 2014 6th International Conference of Soft Computing and Pattern Recognition (SoCPaR). 2014.

[15] Chaurasia, V. and S. Pal, Data mining techniques: To predict and resolve breast cancer survivability. International Journal of Computer Science and Mobile Computing, 2014. 3(1): p. 10-22.

[16] Ahmadi, H., et al., Diseases diagnosis using fuzzy logic methods: A systematic and meta-analysis review. Comput Methods Programs Biomed, 2018. 161: p. 145172.

[17] Aggarwal, P., R. Vig, and H.K. Sardana. Semantic and content-based medical image retrieval for lung cancer diagnosis with the inclusion of expert knowledge and proven pathology. in 2013 IEEE Second International Conference on Image Information Processing (ICIIP2013). 2013.

[18] Farahani, F.V., M.H.F. Zarandi, and A. Ahmadi. Fuzzy rule based expert system for diagnosis of lung cancer. in 2015 Annual Conference of the North American Fuzzy Information Processing Society (NAFIPS) held jointly with 2015 5th World Conference on Soft Computing (WConSC). 2015.

[19] Bawane, K.V. and A.V. Shinde, Diagnosis Support System for Lung Cancer Detection Using Artificial Intelligence. International Journal of Innovative Research in Computer and Communication Engineering, 2018. 6(1): p. 267-274.

[20] Chaurasia, V. and S. Pal, A Novel Approach for Breast Cancer Detection using Data Mining Techniques. International Journal of Innovative Research in Computer and Communication Engineering, 2014. 2(1): p. 24562465 .

[21] Kodati, S. and R. Vivekanandam, Analysis of Heart Disease using in Data Mining Tools Orange and Weka. Global Journal of Computer Science and Technology: C Software \& Data Engineering, 2018. 18(1): p. 17-21.

[22] Mahmoodi, M., L.A. James, and T. Johansen, Automated advanced image processing for micromodel flow experiments; an application using labVIEW. Journal of Petroleum Science and Engineering, 2018: p. 1-31.

[23] P.N.Sharma, A.B.Jadhav, and S.B.Ingle, Studies of different Image Processing Techniques, in 11th 
International conference on Recent Development inEngineering Science ,Humanities and Management. 2018. p. 156-161.

[24] Zhang, X., et al., A Study for Texture Feature Extraction of High-Resolution Satellite Images Based on a Direction Measure and Gray Level Co-Occurrence Matrix Fusion Algorithm. Sensors, 2017. 17(7): p. 1-15.

[25] E.Elalfi, A.E., M.A.-H. Fouda, and A.A. Atta, Developing an Intelligent Decision Support System for the Diagnosis of Some Children's Diseases. International Journal of Computer Applications, 2016. 151(2): p. 3238.

[26] Momeni, A., M. Pincus, and J. Libien, Probability and Probability Distribution, in Introduction to Statistical Methods in Pathology, A. Momeni, M. Pincus, and J.
Libien, Editors. 2018, Springer International Publishing: Cham. p. 39-73.

[27] Manliguez, C., Generalized Confusion Matrix for Multiple Classes. 2016.

[28] Saito, T. and M. Rehmsmeier, The Precision-Recall Plot Is More Informative than the ROC Plot When Evaluating Binary Classifiers on Imbalanced Datasets. Vol. 10. 2015.

[29] Ahsan, M. and M. Kumari, Physical Features Based Speech Emotion Recognition Using Predictive Classification. International Journal of Computer Science and Information Technology, 2016. 8(2): p. 63-74.

[30] Walton, E., et al., Evaluation of sampling frequency, window size and sensor position for classification of sheep behaviour. R Soc Open Sci, 2018. 5(2): p. 1-14. 